\title{
Hilos tensados: para leer el octubre chileno*
}

Kathya Araujo (editora), Antonio Stecher, Vicente Sisto, Lorena PérezRoa, Alejandra Rasse, Pamela Frías, Magdalena Garcés, Lucía Dammert, Pablo Neut, Elke Schlack, Camila Andrade, Álvaro Soto, Carla Fardella, Rosario Fernández, Claudia Moreno, Tai Lin, Mariana Valenzuela, Mauricio Sepúlveda, Ana Vergara, Nelson Beyer, Danilo Martuccelli.

\section{Ximena Orellana Román** y Amaya Pavez Lizarraga***}

Las reivindicaciones sociales impresas en el octubre chileno han perturbado a toda la sociedad. Marcó un punto de inflexión en la historia del país, nadie quedó ajeno a este acontecimiento sorpresivo que se instaló con la fuerza de un colectivo resistente, que venció el miedo y la inercia para defender sus derechos en un ejercicio activo de su ciudadanía.

A la sorpresa y conmoción en la interrumpida cotidianidad, se sumó la necesidad de comprender y explicar el por qué y quiénes estaban detrás de esta movilización general en el país, que interpeló al Estado, al gobierno, a la institucionalidad y a la hegemonía. La proliferación de interpretaciones y comunicaciones desde la diversidad de los espacios sociales buscaron responder a estas preguntas; a pesar de ello, los vacíos persisten, ocultando la fenomenología de la experiencia vivida por la sociedad chilena, que se vislumbra a través de la narración que los y las autoras del libro nos entregan.

La obra comentada busca, en los entresijos de los nudos de la red social, aquellos hilos tensados en la emergencia social y, como señala la editora, entrega un marco de análisis situado que posibilita la com-

Editorial USACH. Colección Idea. Santiago. Año, 2020. 241 páginas. ISBN versión impresa: 978-956-303-437-0. ISBN versión digital: 978-956-303-438-7

** Magíster en Educación, estudiante del Programa de Doctorado de Ciencias Sociales de la Universidad de Chile. Contacto: ximena.orellana@usach.cl

*** Doctora en Antropología, Magíster en Antropología y Desarrollo, académica de la Facultad de Ciencias Médicas de la Universidad de Santiago de Chile. Contacto: amaya.pavez@usach.cl 
prensión del fenómeno en una continuidad histórica en la cual hemos estado inmersos-as, con mayor o menor conciencia, entre la condición individual y de un colectivo fragmentado que se cohesiona en la diacronía de una historia compartida que dejó huellas en las identidades y subjetividades de la chilenidad.

El libro consta de dos partes; la primera aborda los ejes estructurales de la red sociocultural que son comprometidos en sus cimientos, provocando una fisura en la estabilidad social que, por la presión y la sobrecarga, perturba la aparente parsimonia de la vida cotidiana en nuestro país, provocando una erupción con toda la energía acumulada por décadas.

Las pautas para dilucidar este proceso son claves para la comprensión. En lenguaje sencillo explica los procesos que se enraizan en la historia e idiosincrasia de la chilenidad. Una voz narrativa que nos cuenta acerca del pasado, cómo la vivencia contingente se cimienta en una construcción social de la realidad chilena. La lectura es fluida e intensa, abre la conciencia y la autorreflexión, ilustra sobre lo procesos complejos de la historia chilena de los últimos 40 años, rompiendo la verdad cristalizada de una sociedad cimentada en pilares incólumes. La claridad de la exposición posibilita tirar de los hilos que construyen el entramado de nuestra sociedad, para comprender que el devenir social tiene raíces tan fuertes como la voz de octubre. Conocer, comprender estos procesos, permite vernos individual y colectivamente como parte del continuo y, con ello, se consolida la fuerza y validación de la reivindicación, especialmente para los y las protagonistas de octubre, jóvenes que nacieron después de haber construido los pilares de nuestra sociedad del siglo XXI.

La segunda parte cambia la voz narrativa al presente, los escritos están llenos de vivencias, experiencias y contrastes subjetivos, culturales y sociales, que se manifestaron en los meses de octubre a diciembre. La observación situada, analítica, escudriña en la fenomenología de las manifestaciones, cargada de humanidad y realidad, frecuentemente presionada y herida, del pasado al presente, las fisuras sociales se hacen presentes en los cuerpos y corporalidades. Es imposible olvidar esos meses, las emociones mezcladas de alegría colectiva y de dolor muchas veces invisibilizado. 


\section{Elementos para la discusión y el debate de la sociedad actual}

Este libro nos invita a discutir y debatir sobre el presente, un presente que es resultado de un desarrollo histórico, que nos trajo hasta este hoy complejo y lleno de contradicciones no resueltas. Así, a lo largo de los diferentes capítulos, se realiza un esfuerzo de aplicación y demostración de cómo se desenvuelven las contradicciones principales o, en palabras de la compiladora, las tensiones en los distintos ámbitos de la vida social actual: en el mundo del trabajo, en las relaciones laborales, en la crisis de la vivienda, las relaciones de autoridad en la escuela, los feminismos, el malestar instalado en la juventud y en la tercera edad, la transformación del espacio público y el ejercicio de la ciudadanía. A través de estos debates se trasluce, en cada momento, la urgente necesidad de abordaje, por parte de la sociedad chilena, de las promesas incumplidas de democratización de las relaciones sociales.

A continuación, en la narración se intenciona la demostración de los cuatro pilares sobre los que se ha sostenido la actual condición de Chile: la supervivencia de jerarquías naturalizadas, caracterizadas por una sociedad altamente estratificada; la mantención de lógicas de privilegio (de género, étnicas y de clase), sumadas al nepotismo de la clase política; la lógica del autoritarismo, como tradición profundizada por la dictadura, y la confrontación permanente de poderes que se sostienen en el abuso como una constante. Estos pilares han fortalecido el cuestionamiento generalizado, desde incluso antes de octubre de 2019, al debilitamiento y deslegitimación de las instituciones, a los acuerdos y pactos sociales que permitían la mantención de una "aparente normalidad en las relaciones sociales".

La invitación a ir visitando los hilos tensados en la sociedad es una oportunidad para interrogarnos acerca del hoy, pero también de preguntarnos qué nos trajo hasta este presente con desigualdades tan abismantes y proyectar el mañana que queremos vivir. Nos parece entonces de gran valor cuando en el texto se afirma que "octubre no es un estallido por saturación", sino que se corresponde con una disputa por la distribución de poder y las riquezas de la sociedad. ¡Qué importante develar que no es un estallido!, un estallido es una explosión que provoca numerosos daños y nada más. En este caso, el proceso que comienza en octubre de 2019 - y que aún no termina — es más que la 
explosión de la juventud descontenta: ha dado cuenta de la conformación de un conjunto de demandas que no permitirá "continuar gobernando como se ha hecho hasta ahora".

El viaje por los hilos tensados de la sociedad chilena es una lectura gatillante, que se disfruta. Combina adecuadamente los datos empíricos con referencias e incluso cita a fuentes directas, representando un marco conectado con la realidad. En la descripción de las tramas y tensiones de la sociedad actual, nos surge la interrogante - después de la lectura- de qué dirían los autores respecto de algunos hilos tensados que emergen como parte fundamental de la revuelta popular chilena.

En uno de los hilos que se entraman en esta red de relaciones está el movimiento estudiantil, en especial el movimiento de estudiantes secundarios. Ellas y ellos han representado, desde 2001, una perpetua juventud, han sido parte activa de un proceso de movilización continua y, desde hace 20 años, han mantenido tensionada la institucionalidad, instalando demandas como el pase escolar, la democratización de las instituciones educativas, el financiamiento de la educación pública, la crítica al lucro, la gratuidad universal, los abusos y las prácticas sexistas en todos los niveles educativos. En este largo proceso, las distintas generaciones fueron haciendo posta y, generación tras generación, fueron formando a quienes protagonizaron el 18 de octubre y perdieron el miedo, rebasaron la legalidad, sostuvieron y empujaron, abrieron el camino y sentaron las bases de conformación de este gran movimiento nacional, que integra transversalmente generaciones, oficios, géneros, diversidad de roles, e invita a resolver los temas pendientes.

En paralelo, otro de los hilos tensados que queda por entramar en esta red de relaciones propuestas por este libro, es el que hoy se encuentra tensionado gravemente y que hiere en la profundidad el corazón de muchas familias en el país: nos referimos al sistema de salud, que está demostrando la precariedad, la miseria, la desigualdad y los débiles cimientos en que está fundado. Esta tensión ha quedado a la vista en el dolor y sufrimiento de los miles que, por estos días, no han podido ser atendidos o han sufrido pérdidas producto de la desigualdad. Este es un hilo pendiente y que se entrama con los numerosos mencionados en los capítulos de este trabajo; se entreteje con la desigualdad, con el acceso diferenciado según clase a los servicios básicos, con la capacidad de endeudamiento, generado probablemente 
por el tipo de oportunidades laborales, educativas y calidad de vivienda. Hoy queda de manifiesto la connivencia entre las demandas del octubre chileno y la epidemia del covid-19, que nos recuerda que, en el siglo XXI, la salud es un hilo que será necesario refundar. Una falta que cuenta con la corresponsabilidad de quienes ostentan la hegemonía en la toma de decisiones y que repercute en un construcción social de exclusión, de aquí podemos concluir que la revuelta de octubre tiene un largo camino de continuidad.

\section{Reflexiones finales}

El trabajo que comentamos contiene numerosos aportes y colabora con el desarrollo de nuevas explicaciones acerca de la crisis actual en Chile, permite establecer relaciones y vínculos con el desarrollo histórico de nuestro país y representa un avance para profundizar en el debate, abriendo, a través de las diversas aristas abordadas, preguntas e interrogantes sobre las que resultará fundamental buscar respuestas.

Nos parece entonces esencial invitar a la lectura del libro, al público en general y en especial a los jóvenes, pues representa un insumo que permitirá fortalecer procesos formativos en los que se aliente el desarrollo del pensamiento crítico. Asimismo, este trabajo, por su organización temática, facilitará la tarea a quienes quieran comenzar la ruta de profundización e investigación de los hilos que tensan a Chile y que podrían contribuir a una comprensión más acabada de las contradicciones de la sociedad chilena, pues relata los hechos, los describe, los concatena históricamente y los articula con bases teóricas, entregando perspectivas para la comprensión del problema. $\mathrm{Si}$ invitamos a los jóvenes a integrar estos debates en sus experiencias cotidianas, podemos colaborar con la formación de sujetos sociales de pleno derecho.

La lectura reforzará que la revuelta popular chilena es clave en el proceso de construcción de identidades sólidas y en la consolidación de un pacto transgeneracional inédito en las últimas cuatro décadas, que contrasta con el orden y verticalismo institucionalizado, caracterizado por la aversión que tienen las instituciones al conflicto, que ha demostrado incapacidad en la búsqueda de soluciones a los problemas levantados por las continuas movilizaciones. Hostiles a las negociaciones, se sostienen en la presión por el acatamiento a las jerarquías 
y la tendencia a la criminalización de la protesta. ¿Serán atendidas el conjunto de las demandas unificadoras que han surgido desde octubre de 2019? Lo prometido es la instalación de un nuevo pacto social y la renovación de la actual Constitución política, pero ya conocemos la larga historia de los compromisos incumplidos.

El proceso que se ha iniciado en octubre de 2019 tiene un pasado, pero también un futuro, y la pandemia ha dejado al desnudo la crudeza de las desigualdades encarnizadas que es imposible evadir. Existe una relación directa entre los efectos de la contingencia y la pobreza en Chile, que por años ha sido invisibilizada en indicadores de alto desarrollo del país. Por esto, el libro es un gran aporte, al evidenciar procesos e integrar respuestas que aún falta por consolidar, dada la complejidad del fenómeno social que atravesamos. Desde ahí se abren muchas interrogantes que nos interpelan en lo individual y en lo colectivo, haciendo el llamado a los lectores a tomar posición frente a estos hechos y participar en el ejercicio de toma de decisión. En suma, la lectura del libro nos convoca a hacernos conscientes de las decisiones que hay que tomar para el Chile que viviremos. 